\title{
Autologous stem cell transplantation in a case of treatment resistant central nervous system lupus
}

\author{
E Trysberg, I Lindgren, A Tarkowski
}

\begin{abstract}
This case report describes a young woman with systemic lupus erythematosus starting at 16 years of age and giving rise to severe neurological complications including bilateral opticus neuritis and transverse myelitis. Despite heavy immunosuppression her condition steadily aggravated. At this point it was decided to perform autologous stem cell transplantation. Haematopoietic stem cells were mobilised with cyclophosphamide and granulocyte colony stimulating factor. Enrichment of $\mathrm{CD}_{3} 4^{+}$cells was followed by depletion of peripheral $T$ and $B$ cells. The post-transplantation course was uneventful, and all the neurological deficits improved promptly during the 15 months of follow up. This is the first description of successful autologous stem cell transplantation in a case of life threatening central nervous system lupus.

(Ann Rheum Dis 2000;59:236-238)
\end{abstract}

Central nervous system (CNS) involvement has been reported to occur in $14 \%$ to $75 \%$ of patients with systemic lupus erythematosus (SLE). ${ }^{12}$ CNS lupus can occur at any time period during the course of SLE and the symptoms are extremely diverse. Left without treatment CNS lupus is one of the major causes of morbidity and mortality in SLE. ${ }^{3}$ In recent years CNS lupus has been typically treated with cytotoxic drugs that to some extent improve the disease outcome. However, despite this achievement, there are still major problems in controlling disease activity and its progression in many cases of CNS lupus. 28 October 1999
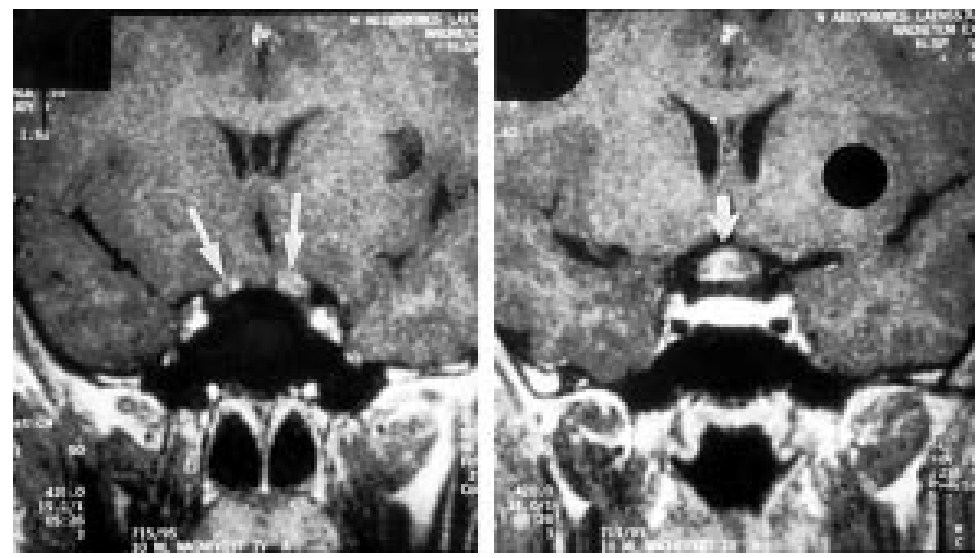

Figure 1 Coronal post-contrast T1 weighted MRI of the brain, showing bilaterally swollen and contrast enhancing opticus nerves (arrows) (left panel) and contrast enhancing chiasma (arrows) (right panel). The analysis was performed on fune 1995.
One possibility for increasing the specificity of the immunosuppressive procedure, used both experimentally in severe rheumatic diseases and in treatment of transplant rejection, is in vivo administration with monoclonal or polyclonal antibodies to T cells. ${ }^{4}$ Another way to treat severe autoimmune diseases before they cause irreversible organ damage would be immune ablation followed by haematopoietic stem cell rescue. ${ }^{5}$ This approach is supported by (1) experimental autoimmune diseases may be arrested by either allogeneic or autologous stem cell transplantation, ${ }^{6}$ (2) patients with leukaemias and/or aplastic anaemias and a concomitant autoimmune disease have been reported to be cured from both diseases after allogeneic bone marrow transplantation. ${ }^{7}$

In this report we present a patient with severe progressive CNS lupus despite treatment with corticosteroids, cyclophosphamide, $\mathrm{T}$ cell antibodies and plasmapheresis. We demonstrate that autologous stem cell transplantation, using stem cells purged of mature $\mathrm{T}$ and $\mathrm{B}$ lymphocytes, showed beneficial long term outcome.

\section{Case report}

A 16 year old, previously healthy woman presented in June 1995, to the Department of Neurology at her local hospital with a six month history of fever, alopecia, bilateral opticus neuritis and transverse myelitis. Magnetic resonance imaging (MRI) of the brain showed different types of lesions including a small plaque close to opticus nerve on the right side, $1.5 \mathrm{~cm}$ long plaque from the level of disc C:3C:4 and one longer plaque from level C:7 down to Th:5 along with swelling and contrast enhancing of both optical nerves and chiasma, all consistent with diagnosis of multiple sclerosis (fig 1). As cerebrospinal fluid showed no oligoclonal bands as would be expected in this condition, she was tested for ANA and anti-dsDNA. ANA was $1 / 320$ with homogenous pattern and anti-dsDNA was also tested positive, $36 \mathrm{IU} / \mathrm{ml}$ (Farr assay), anti-dsDNA IgG 1/80 (Critidia luciliae test).

She was admitted to our hospital in October 1995. Her blood cell counts were within normal limits. Erythrocyte sedimentation rate was $10 \mathrm{~mm} 1 \mathrm{st} \mathrm{h}$. Levels of anticardiolipin antibodies were slightly increased at $34 \mathrm{U}$ (normal < 20U). Complement factor C3 and C4 levels were within normal range. Cerebral spinal fluid at this time showed an increase of interleukin $6(75 \mathrm{pg} / \mathrm{ml}$, normal level $<5$ $\mathrm{pg} / \mathrm{ml})$, slight $\left(4 \times 10^{6}\right.$ cells $)$ pleocytosis, total protein levels within the normal range, and absence of oligoclonal bands. She displayed 
normal kidney and lung functions. A diagnosis of cerebral lupus was suspected, and the treatment started with intravenous methylprednisolone ( $1 \mathrm{~g}$ every other day for three times), and intravenous cyclophosphamide $(1200 \mathrm{mg})$. As a not unusual manifestation of antiphospholipid antibody syndrome is transverse myelitis she was simultaneously given warfarin and low dose aspirin. She made initially a good recovery of her neurological deficit and two weeks later she was discharged home but remained on monthly cyclophosphamide infusions. However, despite intense immunosuppression, seven pulses with cyclophosphamide (1200-1500 $\mathrm{mg}$ at each occasion) and nine pulses with 6 -methylprednisolone $(1000 \mathrm{mg}$ at each occasion) her neurological deficit progressed and in January 1996 she could only read the headlines in the newspaper and had to use a wheelchair for longer transportation than a few metres. MRI in October 1995 showed progress of the pathology in the lower part of cervical spine and upper part of the thoracal spine. At this time treatment with antithymocyte globulin (ATG-Fresenius) started. She received ATG-F, 3-5 mg/kg bodyweight/day over seven days and was subsequently treated with cyclosporin A, $175 \mathrm{mg} /$ day. With this treatment she went into complete remission that lasted for one year. Her hair grew back and the clinical neurological status returned to normal.

At the time of the relapse in February 1997 this patient was treated with the following drugs: low dose corticosteroids ( $5 \mathrm{mg}$ per day), cyclosporin A $175 \mathrm{mg}$ per day, goserelin (GnRH agonist), anticoagulant treatment (dicumarol and low dose acetylsalicylic acid). Findings during the relapse included discoid lupus with hair loss. Slightly later, bilateral opticus neuritis and paraparesis reoccurred, this time concurrently with a neurogenic bladder dysfunction. Despite treatment with 22 pulses with 6-methylprednisolone, 11 pulses with cyclophosphamide every fourth week, 22 plasmaphereses, and another course of anti-
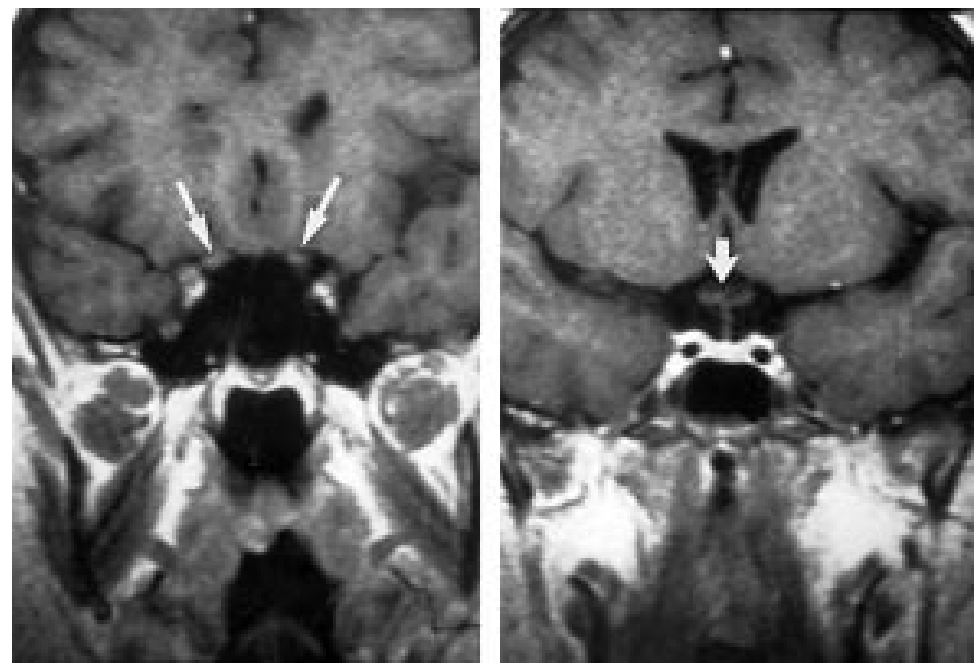

Figure 2 Coronal post-contrast T1 weighted MRI of the brain, showing regression of oedematous changes (see fig 1) in both opticus nerves (arrows) (left panel) and in chiasma (arrows) (right panel). The analysis was performed in August 1998. thymocyte globulin treatment, her neurological deficit progressed.

January 1998 she was wheelchair ridden and almost blind (could only discriminate between light and darkness). At this time it was decided to perform autologous stem cell transplantation. Haematopoietic stem cells were mobilised with intravenous cyclophosphamide bolus ( $4 \mathrm{~g}$ ) and granulocyte colony stimulating factor $(0.3$ $\mathrm{mg} / \mathrm{d}$ for 10 days). Double purging procedure was subsequently performed with enrichment of CD $34^{+}$cells followed by depletion of $\mathrm{T}$ and $\mathrm{B}$ cells using magnetic separation technique. The double purging technique encompasses enrichment of CD $34^{+}$cells followed by depletion of T and $\mathrm{B}$ lymphocytes using monoclonal antibodies (CD4+8 and CD19, respectively) and magnetic beads separation (Baxter, Underschleisheim, Germany). The stem cells were reinfused after conditioning of the recipient with a combination of cyclophosphamide $\left(2470 \mathrm{mg} / \mathrm{m}^{2}\right.$ of body surface at once daily during two days) and total body irradiation (2.5 Gray twice daily during two days). The number of infused CD $34^{+}$cells was $2.5 \times 10^{6} / \mathrm{kg}$ body weight. The contamination of $\mathrm{T}$ cells was minute $\left(1.8 \times 10^{4} / \mathrm{kg}\right.$ body weight $)$ whereas contaminating $\mathrm{B}$ cells were below the detection level ( $<2.5 \times 10^{3} / \mathrm{kg}$ body weight).

After the transplantation the neurological deficits improved promptly and her hair reappeared. Treatment after transplantation included cyclosporin A $100 \mathrm{mg}$ per day, low dose corticosteroids ( $7.5 \mathrm{mg}$ per day) apart from anticoagulant treatment, anti-herpes, anti-fungal, and antibiotic prophylaxis. At present she is able to read without any help devices and walks freely. MRI could verify regression of lesions both in the brain and in the spinal cord (fig 2). ANA, anti-dsDNA and anticardiolipin antibodies primarily disappeared totally but six months after treatment ANA and IgM anti-dsDNA reappeared. The total observation time after the transplantation is now 18 months (October 1999). The patient is continuously performing better with respect to her vision and motor function. However, after the transplantation, the patient experienced four bouts of Coombs test positive haemolytic anaemia, treated on all occasion with corticosteroids. During the period of haemolytic anaemia low complement C4 level is observed. Apart from corticosteroids she has been treated lately with low dose cyclosporin A and azathioprine.

\section{Discussion}

Haematopoietic stem cell transplantation has been suggested as a treatment for severe autoimmune diseases. This case report deals with an adolescent patient having multiple sclerosis-like onset of disease and with time developing full blown SLE characterised by occurrence of ANA and anti-dsDNA antibodies, Coombs test positive haemolytic anaemia, hair loss, and severe multifocal CNS engagement, not responding to advanced immunosuppressive treatment. Treatment with autologous $\mathrm{T}$ and $\mathrm{B}$ cell depleted haematopoietic stem cell transplantation showed excellent 
improvement of treatment resistant CNS lupus. This is a very first description of this type of treatment in CNS lupus. However, five cases of SLE with kidney, lung and blood (Evans syndrome) engagement undergoing autologous stem cell transplantation have been recently reported. ${ }^{8-11}$ The follow up of these patients varied between 4 and 12 months, time period being relatively short to assess the treatment outcome. In this case the follow up time was more than 1.5 years.

Potentially, stem cell transplantation might induce remission of certain SLE manifestations by (1) generation of disease specific tolerance by exposure of immature $\mathrm{T}$ cells to disease provoking molecules, ending up in either anergy or deletion, or (2) recreation of the immune system being unresponsive to the "self" unless re-exposure to the disease initiating stimulus (stimuli) occurs. In this respect autoimmune haemolytic anaemia, observed in this patient after but not before the transplantation, suggests that the expression of different manifestations of SLE might be regulated independantly.

Does transplantation procedure induce remission because of the profound immunosuppression that follows pre-transplantation procedure or is it because of eradication of certain disease propagating lymphocyte clones? This question requires further studies, for example, by use of the similar immunosuppression procedure that should be followed by transplantation of whole leucocyte population including mature antigen comitted lymphocytes.
We thank Dr Brigitte Berthelsen for discussions and excellent radiographic assistance.

Funding: this case report was supported by grants from Göteborg Medical Society, University of Göteborg, The Swedish Association Against Rheumatism.

1 McCune WJ, Golbus J. Neuropsychiatric lupus. Rheum Dis Clin North Am 1988;14:149-67.

2 Hanly JG, Liang MH. Cognitive disorders in systemic lupus erythematosus. Epidemiologic and clinical issues. Ann N Y Acad Sci 1997;823:60-8.

3 Gibson T, Myers AR. Nervous system involvement in systemic lupus erythematosus. Ann Rheum Dis 1975;35: 398-406.

4 Tarkowski A, Andersson-Gare B, Aurell M. Use of anti-thymocyte globulin in the management of refractory systemic autoimmune diseases. Scand J Rheumatol 1993; 22:261-6.

5 Burt RK. BMT for severe autoimmune diseases: an idea whose time has come. Oncology (Huntingt) 1997;11: 1001-14; 17, discussion 18-24.

6 Burt RK, Burns W, Ruvolo P, Fischer A, Shiao C, Guimaraes A, et al. Syngeneic bone marrow transplantation eliminates $\mathrm{V}$ beta $8.2 \mathrm{~T}$ lymphocytes from the spinal cord of Lewis rats with experimental allergic encephalomyelitis. J Neurosci Res 1995;41:526-31.

7 Lowenthal RM, Cohen ML, Atkinson K, Biggs JC. Apparent cure of rheumatoid arthritis by bone marrow transplantation. J Rheumatol 1993;20:137-40.

8 Burt RK, Traynor A, Ramsey-Goldman R. Hematopoietic stem-cell transplantation for systemic lupus erythematosus. [Letter]. N Engl J Med 1997;337:1777-8.

9 Marmont AM, van Lint MT, Gualandi F, Bacigalupo A. Autologous marrow stem cell transplantation for severe systemic lupus erythematosus of long duration. Lupus 1997;6:545-8.

10 Musso M, Porretto F, Crescimanno A, Bondi F, Polizzi V, Scalone R, et al. Autologous peripheral blood stem and progenitor (CD34+) cell transplantation for systemic lupus erythematosus complicated by Evans syndrome. Lupus 1998;7:492-4.

11 Burt RK, Traynor AE, Pope R, Schroeder J, Cohen B, Karlin $\mathrm{KH}$, et al. Treatment of autoimmune disease by intense immunosuppressive conditioning and autologous hematopoietic stem cell transplantation. Blood 1998;92:350514 